on-call junior psychiatrist is suitable to act as nominated deputy.

\section{SAlly-ANN COOPER} RUTH HARPER

University of Leicester

Clinical Sciences Building

Leicester LE2 7LX

\section{Reference}

COOPER, S.-A. \& HARPER, R. (1992) Section 5(2): who acts as the consultant's nominated deputy? Psychiatric Bulletin, 16, 759-761.

\section{Section 5(4)}

\section{DeAR SIRS}

I was disappointed to see this title to an article in the March 1993 issue of the Psychiatric Bulletin as it represents a sad view of editorial policy.

All Acts of Parliament are divided into sections and sub-sections, so this title is meaningless. This is particularly true with the Mental Health Acts of the different countries of the UK, where section numbers do not necessarily coincide with respect to content.

Furthermore, the authors do not at any point in their article include a formal statement of the content of the particular section though they do outline its use. They assume that all readers are familiar with the jargon, because of course that is what it is, of the psychiatric professionals. This is also true of their reference to other sections of the Act, 5(2), 2 and 4.

Professor John Gunn wrote a letter to the Bulletin shortly after the implementation of the Act proposing the use of abbreviated titles for relevant sections so that their general function was apparent to all readers. This proposal has been taken up by the Examinations Sub-Committee for use in the examinations.

I suggest that a similar policy is followed by the Bulletin in particular, and indeed in all situations within the College where sections of the Act are discussed.

\section{Haugh Lane \\ Ecclesall, Sheffield S11 9SA}

Philip Seager

That a description of the function of the particular function of the Act would be a much more useful and appropriate title is accepted and we will endeavour to ensure that this occurs in future. $E d s$.

\section{Audit of in-patient antidepressant use}

DEAR SIRS

Much has recently been written about the use of selective serotonin re-uptake inhibitors (SSRIs) in the treatment of depression where it seems their place has not been established (Ferrier et al, 1992).

To investigate local prescribing habits, a point prevalence survey of antidepressant use in in-patients was undertaken at Bootham Park Hospital in York. On the day of the census there were 96 in-patients, 41 of whom were on antidepressants. More than half of these were on SSRIs (22). Reviewing the case-notes revealed that 14 patients were on antidepressants for the first time (five on SSRIs, nine on tricyclic and related antidepressants (TCAs)). Both the patients on SSRIs and those on TCAs were treated with antidepressants alone, and in combination with lithium, neuroleptics and ECT (except sertraline). SSRIs were prescribed more often than TCAs in those patients with depression plus dementia and those with high suicide risk, as would be expected.

The commonest rationale for specific current antidepressant treatment was suicide risk (four on SRRIs, one on TCA[lofepramine]), intolerance of SSRI/TCA $(2,3)$ and failure of SSRI/TCA $(3,4)$. No written rationale was found in 18 of the 41 patients on antidepressants. Prescription of SSRIs varied between the seven consultants (range $0 / 5$ patients on antidepressants to 6/6)

The results appear to reflect both the current trend towards widespread use of SSRIs and the lack of consensus about their indications. Although the rationale for particular antidepressant use is complex and includes patient, medication and physician factors, to produce a written statement explaining why a particular type of medication is used would be a useful objective for the audit cycle. Regular documentation of reasons behind the prescription of SSRIs and TCAs would be beneficial not only for individual patient management but to aid more focused future research to clarify and perhaps reach consensus regarding the physical management of depression.

\section{Bootham Park Hospital}

Simon L. BALMer

York YO3 $7 B Y$

\section{Reference}

Ferrier, I. N., Silverstone, T. \& Eccleston, D. (1992) Selective serotonin re-uptake inhibitors: use in depression. Psychiatric Bulletin, 16, 737-739.

\section{Cutting costs without cutting corners: a case for sound pharmacotherapy}

\section{DEAR SIRS}

Working for Patients proposed a health care system based on managed competition between care providers with treatments priced in advance. The working Group of the Royal College of Psychiatrists expressed concern about such a system. Glover 